\title{
EFFECT OF PILE COMPRESSIBILITY ON SHAFT FRICTION CAPACITY
}

\author{
Maher AMIRA ${ }^{1}$, Yukimitsu YOKOYAMA ${ }^{2}$ and Shigeyoshi IMAIZUMP \\ ${ }^{1}$ Member of JSCE, Dr. of Eng., Development Division, GEOTOP Corp., (Former Ph.D. Student, Utsunomiya \\ University)(Sankyo Bldg., 17-8 Hakozaki-Cho, Chuo-Ku, Tokyo 103, Japan) \\ 2 Member of JSCE, Dr. of Eng., Professor, Faculty of Eng., Utsunomiya University, (2753 Iishi, Utsunomiya \\ 321, Japan) \\ ${ }^{3}$ Member of JSCE, Dr. of Eng., Associate Professor, Faculty of Eng., Utsunomiya University, (2753 Iishi, \\ Utsunomiya 321, Japan)
}

\begin{abstract}
This paper presents an experimental program to investigate the amplitude of the effect of pile compressibility on the reduction of frictional capacity between downward- and uplift- loading of a single bored pile in sand. For this task, model pipe piles made of three different materials were used in gravity field and in centrifuge apparatus. The amplitude of the reduction was evaluated according to the compressibility parameter $\eta$ defined by De Nicola and Randolph. The ratio of uplift friction resistance to downward friction resistance reached an asymptotic value as $\eta$ increases. The experimental curve of the reduction of frictional capacity and $\eta$ has been found to be different from the analytical one.
\end{abstract}

Key Words: load test, shaft friction, model pile, pile, pull out test, radial strain, compressibility, sand.

\section{INTRODUCTION}

There has been considerable debate over the relative magnitude of pile shaft capacity in tensile (or uplift-) loading, compared with compressive (or downward) loading. In sand, a significant reduction in shaft friction resistance in upliftloading compared to downward loading was mentioned in many model and prototype pile loading tests ${ }^{1)}{ }^{2}$. Concerning the mechanisms involved in the reduction and its amplitude, the available data and analyses are conflicting.

De Nicola and Randolph (1993) ${ }^{3)}$ pointed out three potential mechanisms for such difference as follows:

1) Poisson's ratio expansion and contraction of the pile shaft leading to changes in radial effective stress field in the soil around the pile.

2) Difference in the total stress field, with compressive loading tending to increase and tensile loading tending to decrease the mean stress level in the soil.

3) Changes in mean effective stress due to rotation of the principal stress directions. Depending on the detailed residual stress field along the pile shaft, the degree of principal stress rotation will vary with the direction of loading.
The last of these three mechanisms has been noted from field measurements ${ }^{4}$. However, effects of principal-stress rotation are difficult to quantify theoretically without a sophisticated model of the soil response. By contrast, the first two mechanisms may be explored with relatively simple soil models.

Examination of possible effects of Poisson's ratio of the pile (mechanism 1) has been mentioned by a few researchers. In a discussion given by Fleming et al. (1992) ${ }^{5}$, they explained that the reduction of shaft friction resistance is a result of lower radial stress in the soil owing to tendencies of the pile to contract radially under tensile loading. In an elastic analysis, ensuring compatibility of displacements in the vertical and radial directions, presented to study the working load response of an axially elastic pile embedded in a linearly non-homogeneous incompressible elastic (Gibson) soil, Rajapakse $(1990)^{6}$ ) found that the variation of shaft friction resistance generated does not exceed $6 \%$. In a parametric study conducted by De Nicola and Randolph $(1993)^{3)}$ to explore the theoretical basis for the difference in shaft friction between downward and uplift loading, they showed that the primary cause for lower tensile capacity is due to the 
effect of Poisson's ratio, and that the ratio of tensile to compressive shaft capacity may be expressed as a function of the pile Poisson's ratio, $v_{p}$, the tangent of the friction angle of the pilesoil interface, $\tan \delta$, the relative compressibility of the pile, $G_{a v g} / E_{p}$, and the slenderness ratio, $L / d$, referred to as compressibility parameter $\eta=v_{p} \tan \delta(L / d)\left(G_{a v g} / E_{p}\right)$ (where $G_{a v g}$ is the soil average shear modulus over the depth of $0<z<L)$.

The available investigations of the effect of radial strain (or mechanism 1) on shaft friction resistance are based on analytical methods, except Amira et al. $(1995)^{2)}$ in which the compressibility parameter of the model pile used was very large compared to the compressibility parameter of an actual pile.

This paper presents an experimental attempt to dissociate the effect of mechanism 1 from the other mechanisms. Also, the magnitude of the effect of mechanism 1 on shaft capacity is evaluated by means of the compressibility parameter $\eta$ of the pile.

The laboratory testing program consists of three series of model pile tests in axial uplift- and downward loading. The first, referred to as series 1 , was carried out under gravity field using an acrylic model pile, which gives a large pile-soil compressibility parameter $\eta$. The second, referred to as series 2 , was carried out using an aluminum model pile under the same testing conditions as the first series. The third, referred to as series 3 , was carried out using a steel model pile under centrifugal acceleration. The values of the pile compressibility parameter, obtained from series 2 and series 3 , were realistic.

\section{TESTING EQUIPMENT}

\section{(1) Model piles}

The first and the second model pipe piles are geometrically similar. The first, the acrylic model pile referred to as pile 1, was $25 \mathrm{~mm}$ in diameter with a Young's modulus $E_{p}$ of $2.7 \mathrm{GPa}$, a Poisson's ratio $v_{p}$ of 0.38 and a wall thickness of $2 \mathrm{~mm}$. The second, called pile 2, was an aluminum model pile $24 \mathrm{~mm}$ in diameter with a Young's modulus of $35 \mathrm{GPa}$, a Poisson's ratio $v_{p}$ of 0.31 and a wall thickness of $0.5 \mathrm{~mm}$. For each of these model pipe piles, a steel cone was bonded to the bottom end of the tube. The pile head was fitted with a force transducer. The third model pile, called pile 3, was made from a stainless steel pipe, having a Young's modulus of $196 \mathrm{GPa}$, a Poisson's ratio of 0.2 , a diameter of $10 \mathrm{~mm}$, a

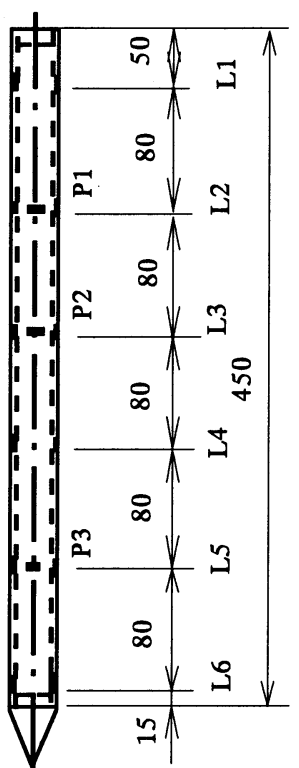

(a) Piles 1 and 2

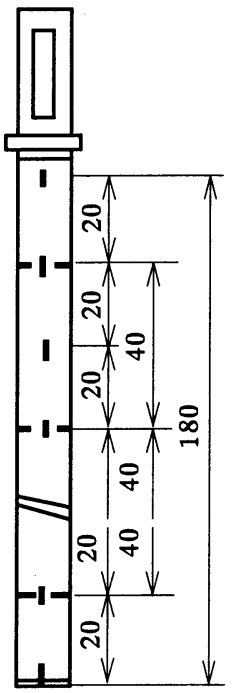

(b) Pile 3
Fig.1 Schemes of (a) Acrylic and aluminum model piles (b) Steel model pile. (Unit: mm)

wall thickness of $0.3 \mathrm{~mm}$ and a length of 200 mm.

Couples of strain gauges were attached at opposite circumferential sides of the pipes, and they were aligned in the longitudinal direction. Other couples were attached in transversal direction of the model pipe pile (see Fig.1).

For protection of strain gauges, the shaft of pile 3 was coated with an acrylic moisture barrier. Hence, the shaft friction was mobilized between the sand and the acrylic coating.

\section{(2) Testing set-up}

The available model testing set-up used for the load tests carried out under gravity field using pile 1 and pile 2 was described in Amira et al. $(1995)^{2}$. It was a rectangular rigid steel container $(600 \times 400 \mathrm{~mm})$ with a depth of $600 \mathrm{~mm}$.

The soil container used in the load tests under centrifugal acceleration used for pile 3 , was a heavily stiffened steel box of $262 \times 242 \mathrm{~mm}$ in plane and $300 \mathrm{~mm}$ in depth, and is shown in Fig.2.

\section{(3) Soil material}

The soil used in the model tests was a clean poorly graded INAGI sand which was sieved to $840 \mu \mathrm{m}$. The maximum and minimum densities were $17.55 \mathrm{kN} / \mathrm{m}^{3}$ and $14.35 \mathrm{kN} / \mathrm{m}^{3}$, respectively. 


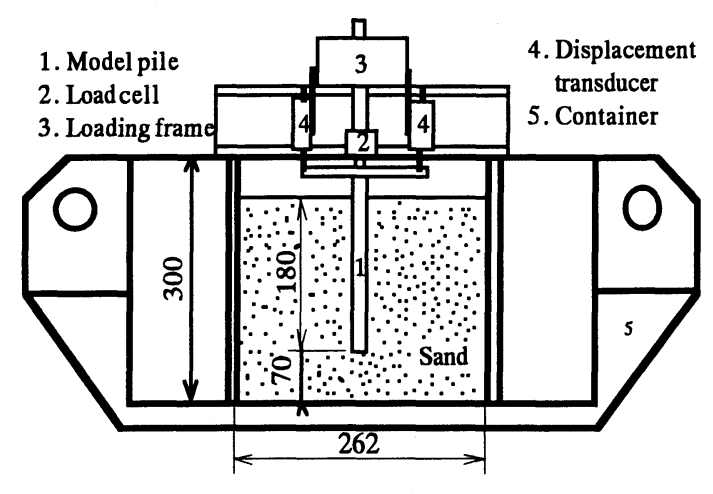

Fig.2 Arrangement of thetesting equipment used in centrifuge (Unit; mm).

The angle of internal friction of the sand obtained by direct shear tests was $42.1^{\circ}$ under relative density of $85 \%$ which was used as a testing condition. The water content of the sand was kept at less than $0.2 \%$. The angles of friction between the sand and pile shaft materials were obtained by direct shear tests. For each pile, a plate, made of the same material as the model pile shaft, was roughened to a similar condition as the model shaft and then placed in the lower part of the direct shear box. The soil was poured in the upper part, then the lower part of the shear box was moved under different normal stress at a displacement rate of $0.5 \mathrm{~mm} / \mathrm{min}$. The friction angles obtained were $29.4^{\circ}, 27.5^{\circ}$ and $29.4^{\circ}$ for pile 1 , pile 2 and pile 3 , respectively.

\section{(4) Model ground preparation}

The model ground was obtained by pluviating sand in air into the container at a constant fall height of $0.53 \mathrm{~m}$, by means of a traveling sand spreader fitted with a hopper having a calibrated rectangular opening of $2 \mathrm{~mm}$. Such a technique ensures soil uniformity ${ }^{7)}$. The samples of the dry sand were prepared at the relative density of $85 \%$.

In the cases of pile 1 and pile 2, the model piles were placed in the center of the container so that a ratio of container width to model pile diameter of $16(400 / 25)$ was obtained which may have minimized the side boundary effects. For the pile embedded depth of $400 \mathrm{~mm}$, the base of the container located about 6 diameters below the pile tip. This distance ratio was considered to be acceptable since it was larger than the distance ratio of 5 suggested by Craig and Sabagh $(1994)^{8)}$.

The same technique was adopted to prepare the sand sample used for load tests on pile 3 . The

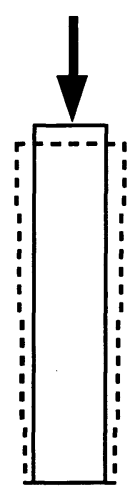

Type a

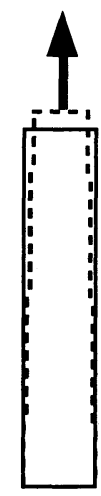

Type b

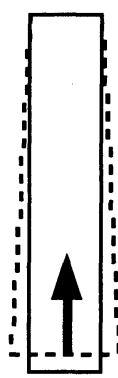

Type c

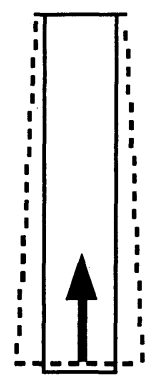

Type d
Fig. 3 Schematic strain according to the type of loading.

testing arrangement limited the maximum embedded length $L$ of the model pile to $180 \mathrm{~mm}$; thus, a length to diameter ratio of 18 was obtained. For the embedded depth, the base of the container located about 8 pile diameters below the pile toe. This ratio was considered to be acceptable as mentioned above.

\section{(5) Loading types}

The types of loading adopted in this test program are shown in Fig.3 and were described in Amira et al. (1995) ${ }^{2}$. They are summarized as follows.

Type(a) was the conventional compressive or downward loading in which the load was applied to the head of the pile and the mobilized shaft friction was taken as a reference for comparison to other types of loading.

Type(b) was the conventional tensile or upliftloading. The pile was subjected to a tensile stress which caused a contraction of the pile shaft due to the effect of Poisson's ratio, leading to the reduction of shaft friction.

Type(c) was an uplift-loading, the originality in it was that the load was applied to the pile toe by means of a stainless steel rod mounted inside the model pipe piles. The lower end of the steel rod was screwed to the steel cone that was bonded to the toe of the pile. The upper end of the steel rod was connected to the loading frame. The pile head was free of any stresses.

Type(d) was also an uplift-loading. The load was applied to the pile toe. The difference from load type(c) was that prior to the loading and after application of surcharge pressure, the model pile was prestressed by a screw to ensure, 
throughout the loading process, the inverted pattern of radial strain mobilized in loading type(a) with approximatly the same maximum and minimum values of radial strain. The different types of loading are shown in Fig.3.

Loading type(d) was not applied to pile 3 in the centrifuge apparatus. Prestress was not able to be applied due to the reduced dimensions of the pile.

\section{TESTING PROCEDURE}

The same model piles were used throughout the course of the testing program. Each pile shaft was roughened before it was tested. Thus no discernible changes in the state of the surfaces were observed due to the repetitive actions of loading.

Following Amira et al. (1995), tests series 1 and series 2 were performed with surcharge pressures applied on the sand surface. The pressures were applied for a period of one hour, in which time complete sand settlement was observed. The surcharge pressures were applied to show the effect of higher stress in the soil on the pile behavior. The surcharges took the values of $49,98,147$ and $196 \mathrm{kPa}$.

In series 3 , the loading process took place under a centrifugal acceleration of $50 \mathrm{~g}$ ( $g$ is the gravity acceleration).

The piles in all types of loading were pushed downward (or pulled-out) at a constant rate of penetration (CRP) of $0.5 \mathrm{~mm} / \mathrm{min}$ for pile 1 and pile 2 and $0.1 \mathrm{~mm} / \mathrm{min}$ for pile 3 . The CRP loading test was developed by Whitaker $(1957)^{9)}$ for model piles and was subsequently used for full-scale pile tests ${ }^{10), 11)}$.

The loading process was completed when a top displacement corresponding to $20 \%$ of the model pile diameter was reached. The ultimate load capacity of a displacement pile was defined as the load that causes a settlement equal to $10 \%$ of the pile diameter ${ }^{12}$. This definition has been extended to non-diplacement piles as a reference bearing capacity in some Japanese design codes.

The strain gauge outputs has been initialized just before surcharge pressures and loads were applied, except in load type(d) where the strain gauges were initialized before the model was prestressed. Therefore, the residual strains due to the sand settlement under the effect of surcharge pressures could be evaluated and distinguished from the strains mobilized by loads.

\section{INTERPRETATION OF THE TEST RESULTS}

\section{(1) Load distribution in piles}

The patterns of load transfer obtained for each pile and each type of loading are similar to the pattern of load transfer obtained for pile 1 and are shown in Amira et al. (1995) ${ }^{2}$. In loading type(c) and type(d), the largest portions of the loads were carried by the lowest part of the pile which can be explained by the large amount of radial strain mobilized near the pile toe due to the application of the load at that point.

The ultimate load capacity in compressive loading [type(a)] is estimated in terms of $F$ and $Q_{b}$, as

$$
Q=F+Q_{b}
$$

where

$Q$ is the total ultimate load capacity of the pile.

$F$ is the total shaft friction resistance of the pile.

$Q_{b}$ is the toe capacity of the pile.

Figures 4a, 4b and $4 c$ show the load-settlement curves of pile 1 , pile 2 and pile 3 , respectively. In these figures, $Q$ and $F$ were plotted versus the ratio of the pile head settlement by the pile diameter $\left(w_{c} / d\right)$. The toe resistance $Q_{b}$ was plotted versus the ratio of toe settlement by pile diameter $\left(w_{b} / d\right)$. The analysis of these figures shows that up to a $\left(w_{c} / d\right)$ of about $12 \%$ the total shaft friction resistance of pile 1 and pile 2 are much larger than the toe resistance. On the contrary, for a pile head settlement larger than the prementioned value, it was observed that the toe resistance increased at a gradual decreasing rate to become larger than the shaft friction resistance.

For pile 3, it was observed that up to a head settlement $\left(w_{c} / d\right)$ of about $10 \%$, the pile behaved as friction pile, which corresponds to a peak in total shaft friction resistance. The toe resistance was mobilized when the settlement of pile head exceeded the prementioned value.

The difference in pattern of the curves of loadsettlement between the first two piles and the third one could be attributed to the difference in testing conditions. The applied surcharge pressure on the sand surface mobilized a settlement of sand which in turn mobilized a settlement of the first two piles. The observed settlement compacted the zone of remolded loose sand under the toe. The same settlement was observed in pile 3 , but its 


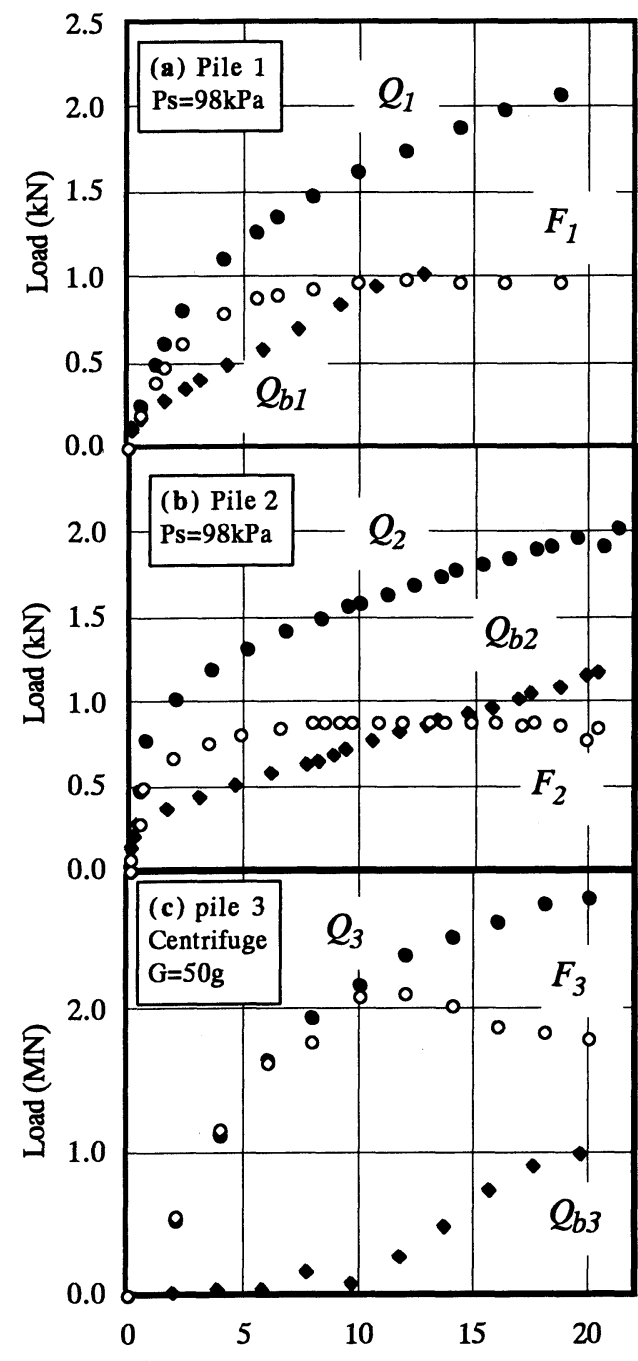

Pile head or toe settlement $\%\left(w_{c} / d\right)$ or $\left(w_{b} / d\right)$

Fig. 4 Load-settlement curves of the components of load capacity.

amplitude was found to be smaller under the effect of centrifugal acceleration.

Since pile 1 and pile 2 are geometrically similar, a comparison between their total shaft friction resistance and their toe resistance at a pile head settlement $w_{c} / d=10 \%$, is shown in Fig.5. The figure shows the variation of the toe resistance and the total shaft friction resistance at various surcharge pressures.

The total shaft friction resistance of pile 1 was found to be larger than that of pile 2 . In contrast the toe resistance of pile 1 was smaller than that of pile 2. The higher shaft friction and lower toe resistance of pile 1 compared to those of pile 2 was attributed to the high deformability of pile

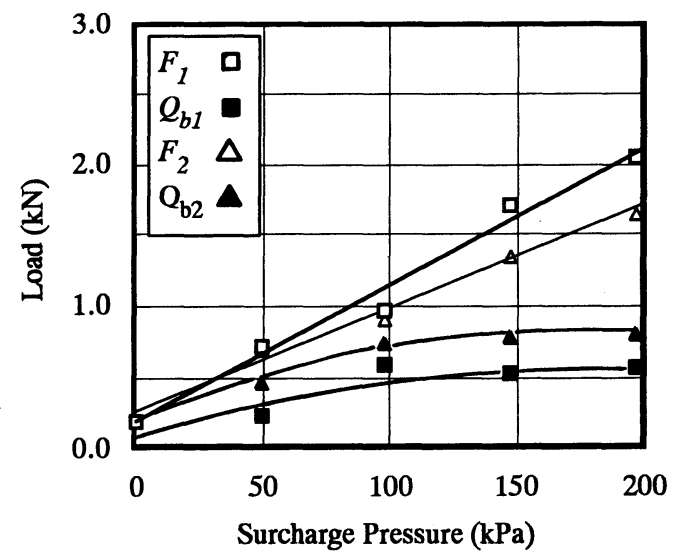

Fig.5 Effect of pile materials on the shaft frction resistance and toe resistance of loading type(a) at $w_{c} \int d=10 \%$.

1. For the same pile head settlement, the toe settlement obtained in pile 2 was larger than that of pile 1. This is due to the elastic shortening of pile 1 which was larger than that of pile 2 .

Also by considering the ratios of the total shaft friction resistance by the toe resistance $F_{1} / Q_{b_{1}}$ and $F_{2} / Q_{b_{2}}$ corresponding respectively to pile 1 and pile 2, it was found that $F_{1} / Q_{b_{1}}>F_{2} / Q_{b_{2}}$.

The ratio of the total shaft friction to the toe resistance $F_{3} / Q_{b_{3}}$ of pile 3 was found to be very large compared to the ratio of the first two piles. The reduction in the toe resistance of pile 3 could be attributed to the installation of the model pile, which left under the model pile toe a zone of remolded and loose sand.

\section{(2) Total friction-displacement relationship}

The key parameters that may affect the total shaft friction resistance may be grouped into the following non-dimensional ratios 3 )

$$
F=f\left(v_{p}, \frac{L}{d}, \frac{E_{p}}{G_{a v g}}, \frac{G}{f_{s}}, v_{s}\right)
$$

where

$v_{s}$ is the Poisson's ratio of the soil

$f_{s}$ is unit shaft friction

$G$ is the soil shear modulus

$L / d$ and $G_{a v g} / E_{p}$ are given in the introduction of this paper

The shaft resistance of a drilled shaft under drained conditions is given by 


$$
F=\pi d \int_{0}^{L} \sigma_{v}^{\prime}(z)_{K}(z) \tan \delta d z
$$

As it was mentioned in the previous section, the ultimate total shaft friction resistance of pile 1 was larger than that of pile 2 . The difference in total shaft friction obtained can also be, to a large degree, attributed to the effect of radial strain which generated a much larger expansion of the diameter of pile 1 than that of pile 2 .

The variation of total shaft friction resistance for the various loading types was plotted versus the pile head settlement $w_{c} / d$ in Figs 6. As this figures show, the ultimate shaft frictions increased in the following order type(b), type(c), type(d) and type(a).

The same figures show that the ultimate total shaft friction of type(a) and type(b) required a pile head displacement of 10 to $15 \%$ of the pile diameter, while loadings type(c) and type(d) required pile head displacement of 5 to $10 \%$ the pile diameter. Therefore, by applying the load at the pile toe [loadings type(c) and type(d)], the largest displacement occured near that point. The resulting pile head displacement was found to be smaller due to the pile shortening under axial compressive loading.

Table 1 draws up a comparative summary of the results of Figs.6a, $6 \mathrm{~b}$ and $6 \mathrm{c}$ in which the ultimate total shaft frictions $F_{b}, F_{c}$ and $F_{d}$, corresponding to loadings type(b), type(c) and type(d), respectively, were divided by the ultimate total shaft friction $F_{a}$ corresponding to loading type(a). It shows a reduction of the ultimate total friction resistance for the uplift-loading tests type(b) compared to that of the down-loading tests type(a).

On the average, the ratio $F_{b} / F_{a}$ for the different cases of surcharge pressures was 0.50 for pile 1 , 0.53 for pile 2 and 0.60 for pile 3 .

By applying the axial uplift-loading at the pile toe (loading type(c)), the pile diameter expanded radially which resulted in an average recovery of about $11 \%, 7 \%$ and $5 \%$ of the ultimate total shaft friction resistance mobilized in loadings type(a) of pile 1 , pile 2 and pile 3, respectively, as shown in Table 2.

The ratios of total ultimate shaft friction of test type(d) to the total ultimate shaft friction of tests type(a), of pile 1 and pile 2, is approximately 0.80 and 0.66 respectively as summarized in Table 1. The test type(d) could not be performed with pile 3.

By applying to the piles the same inverted pattern of radial strain, as was mobilized in
Table 1 Reduction in shaft friction due to loading types(b, c, \& d) with reference to type(a).

\begin{tabular}{|c|c|c|c|}
\hline & Pile 1 & Pile 2 & Pile 3 \\
\hline$\eta$ & $54 \times 10^{-3}$ & $3.6 \times 10^{-3}$ & $0.4 \times 10^{-3}$ \\
\hline$F_{b} / F_{a}$ & 0.50 & 0.53 & 0.60 \\
\hline$F_{d} / F_{a}$ & 0.61 & 0.60 & 0.65 \\
\hline$F_{d} / F_{a}$ & 0.80 & 0.66 & $\cdots \cdots$ \\
\hline
\end{tabular}

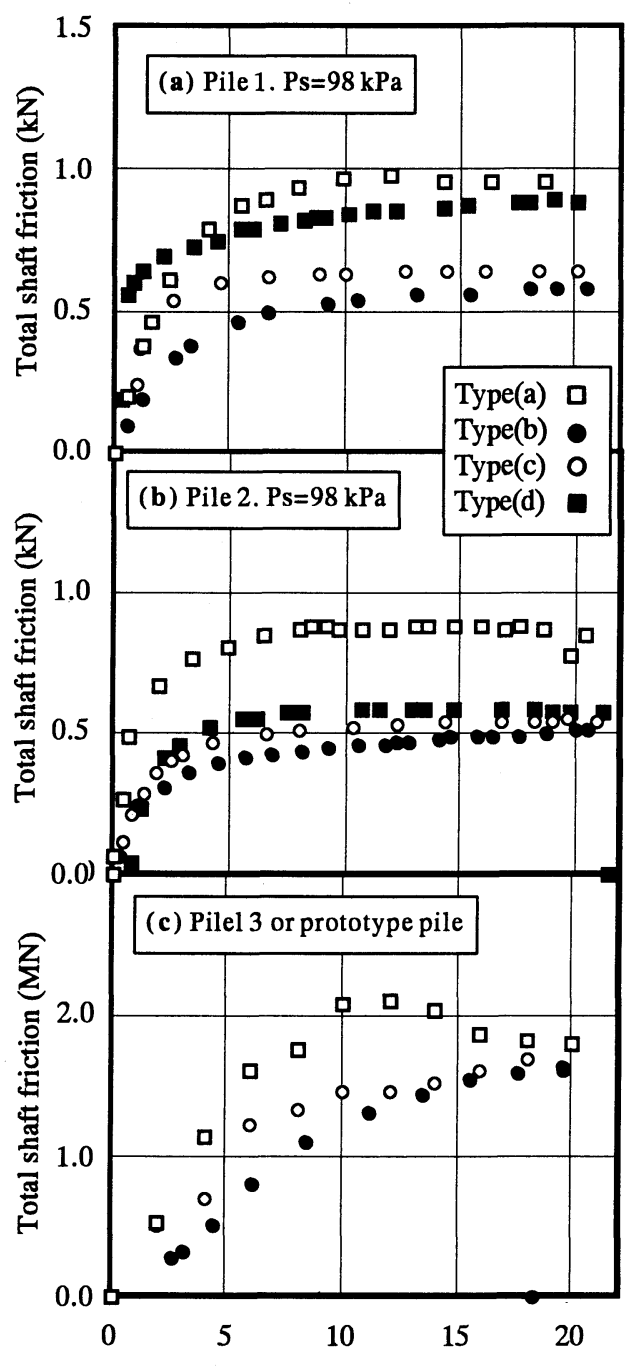

Pile head displacement $\left(w_{c} / d\right) \%$

Fig.6 Total friction-displacement curves for the different type of loading.

loading type(a), about $30 \%$ and $13 \%$ of the total ultimate shaft friction resistance was recovered for pile 1 and pile 2, respectively. This means that $30 \%$ of $50 \%$ and $13 \%$ of the $47 \%$ of the reduction between the ultimate total shaft friction in loading type(a) and that of loading type(b) of 
Table 2 Recovery of shaft friction generated by loading types(c \& d) with reference to type(b).

\begin{tabular}{|c|c|c|c|}
\hline & Pile 1 & Pile 2 & Pile 3 \\
\hline$\eta$ & $54 \times 10^{-3}$ & $3.6 \times 10^{-3}$ & $0.4 \times 10^{-3}$ \\
\hline$F_{d} / F_{a}-F_{b} / F_{a}$ & 0.11 & 0.07 & 0.05 \\
\hline$F_{d} / F_{a}-F_{b} / F_{a}$ & 0.30 & 0.13 & $\cdots$ \\
\hline
\end{tabular}

pile 1 and pile 2, respectively, resulted from the difference in radial strain generated in the piles.

In test type(a) and type(d), the opposite directions of loads; downward loading for test type(a) and uplift loading for test type(d), could mobilize other phenomena such as mechanism 3 and mechanism 2 , in other words the later could be explained by arching in the sand, which tends to increase the total stress field with compressive, loading while its absence tensile loading tends to decrease the mean stress level in the soil.

The analysis of the average ratio $\left(F_{b} / F_{a}\right)_{3}$ of pile 3 was larger than the ratio $\left(F_{b} / F_{a}\right)_{2}$ of pile 2 , which was, in turn, larger than the ratio $\left(F_{b} / F_{a}\right)_{1}$ of pile 1. The observed differences in frictional ratios are due to the radial contraction of the model pile which was larger in pille 1 than in pile 2 than in pile 3 . The decrease in the $\operatorname{ratio}\left(F_{b} / F_{a}\right)$ from pile 3 to pile 2 to pile 1 was mostly attributed to the difference in the radial strain mobilized in these piles.

Fig.7 shows the variation of the ratio of unit friction $f_{s} / \sigma_{v}$ with the radial strain generated in pile 1 and pile 2 . The radial strain considered here wass obtained when the full unit shaft resistance is mobilized. This figure of radial strains is similar to the one shown in Amira et al. $(1995)^{2)}$, the radial strain mobilized in pile 2 varied between -200 and $800 \mu$.

(3) Unit friction

The average unit shaft friction resistance $\bar{f}_{s}$, mobilized in loading tests under unity gravity, was estimated as the total ultimate friction divided by the surface area of the model pile. Fig.8a and $\mathbf{8 b}$ show the variation of the unit shaft friction, mobilized by the loadings type(a), type(b), type(c) and type(d), with the vertical earth pressure within the sand for pile 1 and pile 2, respectively. The analysis of these figures shows that the average unit friction $\overline{f_{s}}$ increased with the increasing of the vertical stress in soil and the rate of increase obtained in loadings type(a) and type(d) was larger than that of loadings type(b) and type(c) which means that the effect of radial strain of a pipe pile on unit shaft friction became much more important with depth.

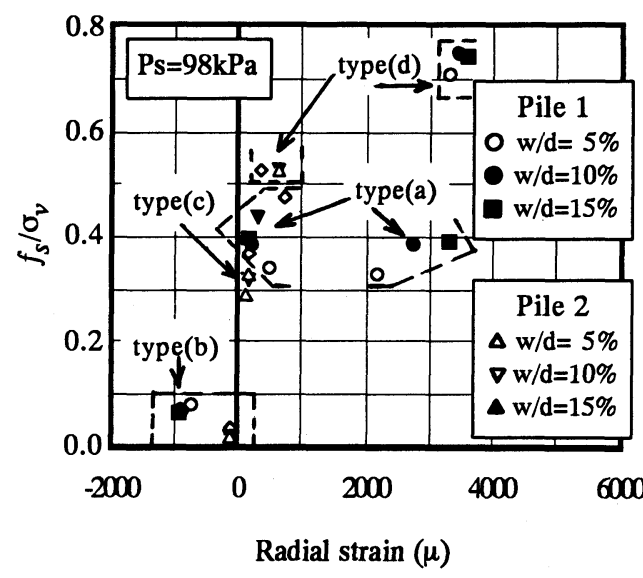

Fig.7 $\left(f_{s} / \sigma_{v}\right)$ vs radial strain generated in pile 1 and pile 2 by the different types of loading.

The average values of unit shaft frictions of pile 1 and pile 2 , mobilized in load tests under unity gravity with applied surcharge, was found to be smaller than the unit shaft friction of the prototype pile (or pile 3 ) in the sub-layer of soil presenting a level of vertical stresses equal to those obtained by surcharge pressures (See Fig.8c). The difference in unit shaft friction between prototype and reduced scale model pile, could also reflect the effect of arching in sand in radial direction. Due to this effect, the reduction of unit shaft friction could be considerable in case of piles with a reduced diameters.

\section{EFFECT OF PILE COMPRESSI- BILITY ON SHAFT FRICTION}

The clearest trends were obtained by evaluating the experimental friction ratio $\left\{F_{b} / F_{a}, F_{d} / F_{a}\right.$, $\left.F_{d} / F_{a}\right\}$ and $\left\{\left(F_{d} / F_{a}\right)-\left(F_{b} / F_{a}\right),\left(F_{c} / F_{a}\right)-\left(F_{b} / F_{a}\right)\right\}$ as a function of the product $v_{p} \tan \delta(L / d)\left(G_{a v g} / E_{p}\right)$ designated by the compressibility parameter $\eta$ (see Table 2), and plotting them as shown in Fig.9 and Fig.10. In these representations $G_{\text {avg }}$ was given ${ }^{13)}$ the value of about $43 \mathrm{MPa}$ and $v_{s}=0.33$.

In Fig.9, it can be seen that the ratio $\left(F_{b} / F_{a}\right)$ decreased to reach an asymptotic minimum as the compressibility parameter $\eta$ increased.

A frictional ratio $F_{b} / F_{a}$ derived theoretically and verified numerically ${ }^{3)}$ for the effect of Poisson's ratio was compared to the experimental results in Fig.9. The figure shows a critical compressibility parameter $\eta_{c}$ of about 0.065 at which the two curves intersected. It can be also 


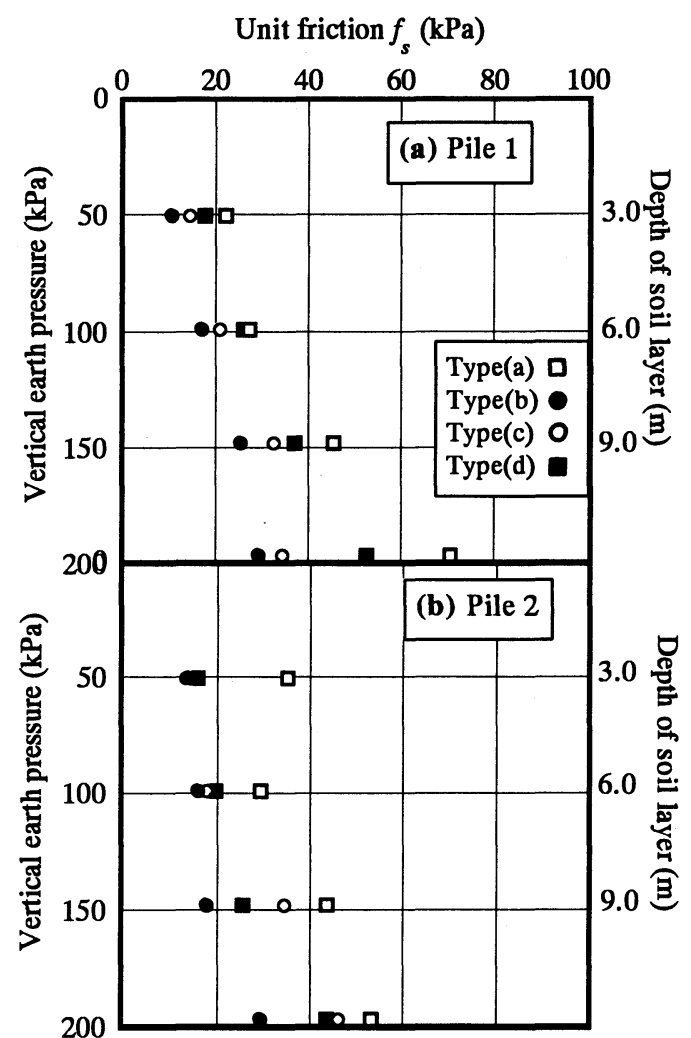

Fig.8 (a \& b) Variation of unit shaft friction of pile 1 and pile 2 with the soil vertical stress.

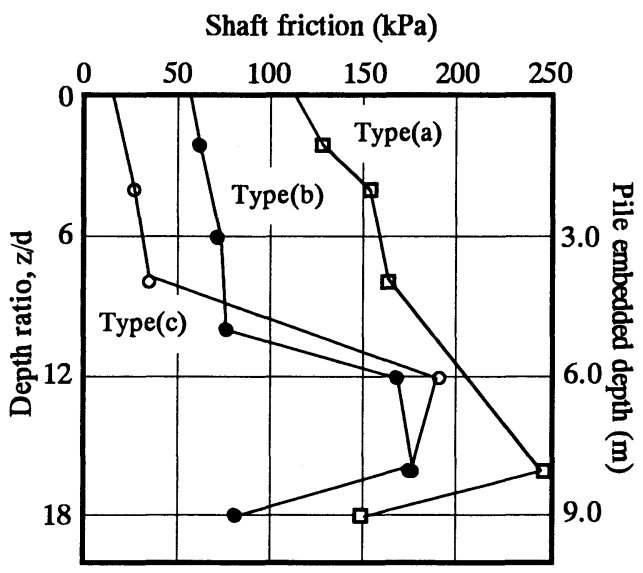

Fig.8c Unit shaft friction profiles of the prototype pile or pile 3 .

seen that when $\eta<\eta_{c}$, the theoretical frictional ratio exceeds the experimental one, while $\eta>\eta_{c}$, the theoretical frictional ratio underestimates the experimental one. For $\eta<\eta_{c}$ the difference could

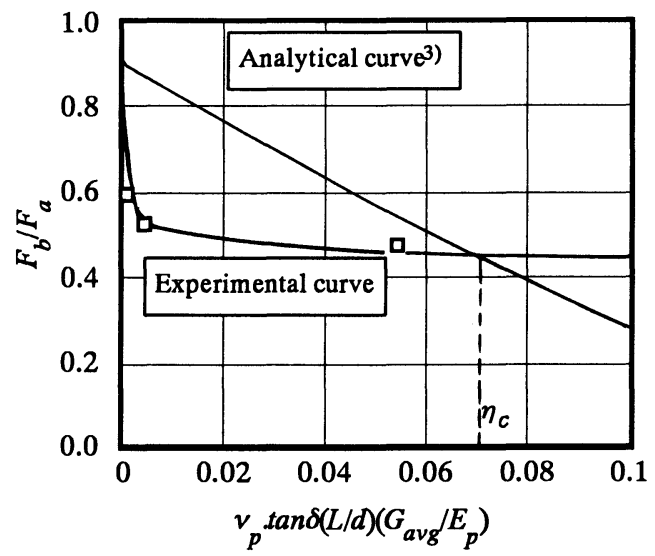

Fig.9 Effect of Poisson's ratio contraction on the uplift friction resistance.

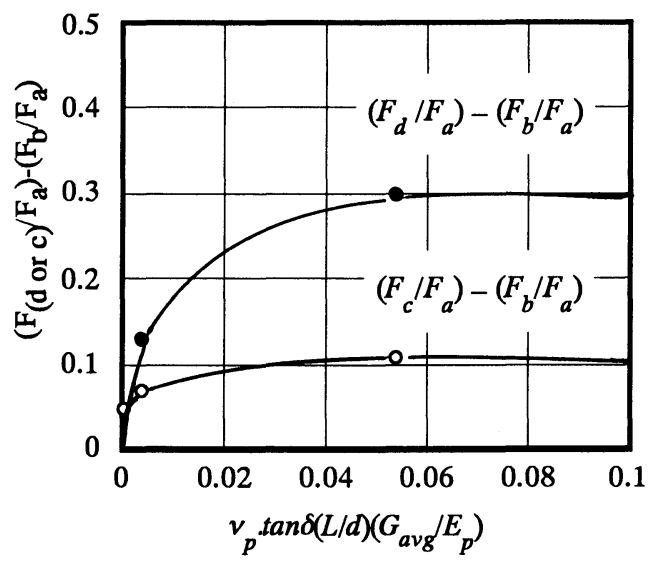

Fig.10 Recovery of shaft friction resistance generated by the expansion due to Poisson's ratio.

be attributed to the fact that mechanism 2 and mechanism 3 were not considered while for $\eta>\eta_{c}$ the theoretical curve assumes a non realistic large contraction of the pile diameter under the tensile stress.

Fig.10 shows the curves of recovery in shaft friction resistance produced by loading type(c) and type(d), by reference to loading type(a), The two curves increased to reach an asymptotic maximum of 0.12 and 0.30 , respectively. Therefore, an increasing value of the compressibility parameter $\eta$ is favored for shaft friction resistance when the pile shaft is subjected to a compressive stress. Loading type(a), type(c) and type(d) provided the compressive stresses in the pile shaft disregarding the direction of loading.

The results of the experimental analysis, just described above, came from two possible separate 
mechanisms for differences in tensile and compressive shaft capacity. The effects of changes in mean stress in soil due to the direction of loading must be dissociated from those due to Poisson's ratio causing expansion or contraction of the pile.

\section{CONCLUSIONS}

The test results showed that the ratio of tensile shaft friction to compressive shaft friction $F_{b} / F_{a}$ sharply decreases for the compressibility parameter $0<\eta<0.02$ and reach an asymptotic value of about 0.4 .

The effect of Poisson's ratio contraction and expansion of the pile on the shaft capacity ratios $F_{b} / F_{a}$ showed that they depend on the compressibility parameter $\eta$ of the pile. In actual solid cross section pile this effect on total shaft friction would be about 5\%.

The recovery of tensile shaft friction obtained by loadings type(c) and type(d) sharply increases for the compressibility parameter $0<\eta<0.04$ and reach an asymptotic value of about 0.12 and 0.30 , respectively.

Loading of type(c) or type(d) could be prominent in case of pile having a compressibility parameter larger than $\eta=0.04$. Also the loading of these types mobilized the full shaft friction for lesser pile head displacement.

The experimental relationship between the ratio $F_{b} / F_{a}$ and $\eta$ diverged with the analytical approach proposed by De Nicola and Randolph (1993) ${ }^{3}$, due to the fact that this solution did not consider the effect of mechanism 2 and mechanism 3.

ACKNOWLEDGMENTS: The authors gratefully acknowledge many useful comments and suggestions that they have received from Professor Hideaki Kishida and Dr. Hideki Hirayama regarding the content of the paper. The authors also wish to thank Messrs. Sadao Yabuuchi, Takashi Horiguchi of GEOTOP Corporation, for their support and cooperation.

\section{REFERENCES}

1) Kanakapura, S., Rao, S. and Venklatesh, K. H.: Uplift behaviour of short piles in uniform sand, Soils and Foundations, JSSMFE, Vol. 25, No. 4, pp. 1-7, 1985.

2) Amira, M., Yokoyama, Y. and Imaizumi, S.: Friction capacity of axially loaded model pile in sand, Soils and Foundations, JSSMFE, Vol. 35, No. 1, pp. 75-82, 1995.

3) De Nicola, A. and Randolph, M. F.: Tensile and compressive shaft capacity in sand, Jour. of Geotech. Eng., Vol. 119, No. 12, ASCE, pp. 1952-1973, 1993.

4) Lehane, B. M., Jardine, R. J., Bond, A. J. and Frank, R.: Mechanisms of shaft friction in sand from instrumented pile tests, Jour. Geotech. Eng., Vol. 119, No. 1, ASCE, pp. 19-35, 1993.

5) Fleming, W.G.K., Weltman, A.J., Randolph, M.F. and Elson, W.K.: Piling Engineering, 2nd ed., John Wiley \& Sons, New York, p. 100, 1992.

6) Rajapakse, R. K. N. D.: Response of an axially loaded elastic pile in a Gibson soil, Canadian Geotech Jour., Vol. 40, No.2, pp. 237-249, 1990.

7) Passalacqua, B.: Sand-spreader used for the reconstitution of granular soil models, Soils and Foundations, JSSMFE, Vol. 31, No. 2, pp. 175-180, 1991.

8) Craig, W.H. and Sabagh, S.K.: Stress level effects in model tests on piles, Canadian Geotech. Jour., 1994.

9) Whitaker, T.: Experiments with model piles in groups, Geotechnique, Vol. 7, pp147-167, 1957.

10) Whitaker, T. and Cooke, R. W.: A new approach to pile testing, Proceedings of the 5th ICSMFE, Vol. 2, pp. 171176. 1961.

11) Whitaker, T.: The constant rate of penetration test for the determination of the ultimate bearing capacity of a pile, Proceedings of the Institutions of Civil Engineering, Vol. 26, pp. 119-123, 1963.

12) Terzaghi, K.: Discussion of the progress report of the committee on the bearing value of pile foundations, Proceedings, ASCE, Vol. 68, pp. 311-323, 1942.

13) Horikoshi, T.: Study of end bearing capacity of pile foundation, Master's thesis, Department of Civil Engineering, Utsunomiya Univ., pp. 20-79, 1987 (in Japanese).

(Received July 27, 1995) 


\section{杭の圧縮性が摩擦抵抗に及ぼす影響}

\section{アミラ マヘル・横山 幸満・今泉 繁良}

杭の軸方向及び半径方向の変形性が, 埋込み杭の押込み時及び引抜き時の杭周面摩擦抵抗に及ぼす影響を 3 種 類の材料 (アクリル,アルミ及び鋼) を用い,4 種類の載荷方法 (杭頭押込み及び引抜き, 杭底部引抜き 2 種) で模 型実験 (通常の砂箱と遠心)により実験的に考察した. 押込み抵抗に対する引抜き抵抗の減少を, 杭材料のポアソ

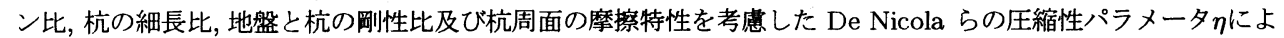
り評価した. 押込み摩擦抵抗に対する引抜き摩擦抵抗の低下率は, $\eta$ の増加とともにある漸近值に到達し, 摩擦抵 抗の低下を表す奉験曲線は, 解析值と異なることを述べている. 